\section{Storage Temperature Affects the Quality of Cut Flowers from the Asteraceae}

\author{
Fisun G. Çelikel ${ }^{1}$ and Michael S. Reid \\ Department of Environmental Horticulture, University of California, Davis, \\ CA 95616
}

Additional index words. gerbera, sunflower, respiration, vase life, negatively gravitropic bending, temperature

\begin{abstract}
The respiration of cut flowers of gerbera (Gerbera jamesonii H. Bolus ex Hook.f. 'Vesuvio') and sunflower (Helianthus annuus L.) increased exponentially with increasing storage temperature. Poststorage vase life and negatively gravitropic bending of the neck of the flowers were both strongly affected by simulated transport at higher temperatures. Vase life and stem bending after dry storage showed highly significant linear relationships (negative and positive, respectively) with the rate of respiration during storage. The data indicate the importance of maintaining temperatures close to the freezing point during commercial handling and transport of these important commercial cut-flower crops for maximum vase life.
\end{abstract}

Gerbera and sunflower, members of the Asteraceae, are important floricultural crops, and their share of the market for cut flowers has increased in recent years. We recently monitored temperature during transport for flowers harvested in California and shipped by truck across the United States, and have found that temperatures are usually higher than what we consider ideal: 0.5 to $1.5^{\circ} \mathrm{C}$ (33 to $35^{\circ} \mathrm{F}$ ). The benefits of low temperatures in the storage of cut flowers have long been known (Carow, 1978; Hardenburg et al., 1986; Jones and Moody, 1993; Maxie et al., 1973; Nowak and Rudnicki, 1990; Sacalis, 1993).

The high respiration rate of cut flowers (Maxie et al., 1973) is presumed to be the basis for the deleterious effects of storage at warmer temperatures. Until recently, however, there have been few studies of the effect of different transport temperatures on the posttransport life of flowers, and there have been none on gerberas and sunflowers. One of the common quality defects in gerberas and sunflowers is bending of the neck (Sang et al., 1998), and we decided to test the hypothesis that such bending was a result of negatively gravitropic growth during horizontal transport at warmer temperatures. To avoid desiccation during transport and to ameliorate stem bending, growers have started transporting cut flowers vertical in Procona System containers (Pagter Innovations, Dinteloord, The Netherlands) or other transport boxes that allow them to be shipped in water. We therefore also tested the effect of temperature on the vase life of flowers that were subjected to simulated transport in water.

Received for publication 27 Dec. 2000. Accepted for publication 7 May 2001. This research was supported by funding from the American Floral Endowment and by a grant from the Ministry of Agriculture in Turkey. We also thank Adel Kader and Shimon Meir for reviewing the manuscript.

${ }^{1}$ Atatürk Central Horticultural Research Institute, 77102 Yalova, Turkey.E-mail address: fgcelikel@ ttnet.net.tr

\section{Materials and Methods}

Plant material. Gerberas and sunflowers grown in California were obtained from a local wholesale distributor and used in experiments within $24 \mathrm{~h}$.

Respiration measurement. The effect of temperature (ranging from 0 to $20{ }^{\circ} \mathrm{C}$ ) on respiration was determined using the "dynamic"system described by Cevallos and Reid (2000), in which we followed respiration of individual flowers over the whole temperature range. A single flower was cut just below the capitulum, placed in deionized (DI) water, and sealed in a jar ventilated with a flowing stream of $\mathrm{CO}_{2}$-free (obtained by passing air through a soda-lime column) air at a flow rate $\left(4 \mathrm{~L} \cdot \mathrm{h}^{-1}\right)$ sufficient to prevent $\mathrm{CO}_{2}$ concentrations from rising above $500 \mathrm{ppm}$ at the highest temperature used $\left(20^{\circ} \mathrm{C}\right)$. The jar was submerged in a $30 \%$ glycol bath (LAUDA K-4/R; Brinkmann Instruments, Westbury, N.Y.), providing precise control of temperature. Respiration of the flower was determined by continuously recording the $\mathrm{CO}_{2}$ concentration at the outlet of the jar using an infrared gas analyzer (Qubit Systems Inc., Kingston, Ont., Canada).

The flowers were held overnight at $20^{\circ} \mathrm{C}$ in the respiration chamber to dissipate any effects of handling on respiration. The $\mathrm{CO}_{2}$ concentration was recorded; then the temperature of the bath was changed to $15^{\circ} \mathrm{C}$. After a stable $\mathrm{CO}_{2}$ reading was obtained $(1.5 \mathrm{~h})$, the temperature of the bath was further reduced to $12.5^{\circ} \mathrm{C}$ and, after similar time intervals, to 10 , $7.5,5,2.5$, and $0^{\circ} \mathrm{C}$. The effect of temperature on respiration was measured in this manner for at least three replicate flowers.

Wet and dry storage. To determine the effect of storage temperature on subsequent vase life at $20{ }^{\circ} \mathrm{C}$, flowers were recut to a length of $40 \mathrm{~cm}$, and six replicate stems were wrapped in newspaper and polyethylene and packed dry in a fiberboard box. Replicate stems of gerbera flowers were also placed in vases containing DI water for "wet" storage. The gerbera flowers were then stored at tem- peratures ranging from 0 to $12.5^{\circ} \mathrm{C}$ for $5 \mathrm{~d}$. Sunflowers were stored dry at temperatures ranging from 0 to $15^{\circ} \mathrm{C}$ for $6 \mathrm{~d}$.

Determination of vase life. After storage, the flowers (six replicate stems per temperature) were recut to $35 \mathrm{~cm}$ under water. Gerberas were placed in a vase solution of $50 \mathrm{ppm}$ $\mathrm{NaOCl}$ (chlorine bleach), and sunflowers were placed in DI water. The flowers were held during their vase life in a controlled-environment vase life evaluation room kept at $20{ }^{\circ} \mathrm{C}$ and $60 \%$ relative humidity. Artificial light (15 $\mu \mathrm{mol} \cdot \mathrm{m}^{-2} \cdot \mathrm{s}^{-1}$ photosynthetically active radiation) was provided $12 \mathrm{~h}$ /day from cool-white fluorescent tubes (Sylvania Lighting Co., Danvers, Mass.). The flowers were examined daily, and their vase life was recorded as the time to wilting of the flowers or excessive bending of the scape. After $2 \mathrm{~d}$ in the vase, the diameter of each inflorescence was determined for the sunflowers.

Determination of stem bending. The stem bending in gerberas and sunflowers after dry storage and during vase life was determined daily by estimating the angle between the main stem and the stem just below the capitulum. The gerberas were rated as follows: 0 for bending up to $15^{\circ} ; 1$ for bending between 15 and $25^{\circ} ; 2$ for bending between 25 and $65^{\circ} ; 3$ for bending between 65 and $90^{\circ}$; and 4 for flowers bent more than $90^{\circ}$. The sunflowers were rated: 1 for slight bending up to $45^{\circ} ; 2$ for moderate bending between 45 and $90^{\circ}$; and 3 for advanced (downward) bending more than $90^{\circ}$.

Statistical analysis. Data were statistically analyzed using one-way analysis of variance and Tukey's multiple comparison test. Respiration data were subjected to regression analysis.

\section{Results}

Effect of temperature on respiration. The respiration of gerberas (Fig. 1a) and sunflowers (Fig. 2a) increased exponentially with increasing temperature. The $\mathrm{Q}_{10}$ values for respiration between 0 and $10{ }^{\circ} \mathrm{C}$, and 10 and $20{ }^{\circ} \mathrm{C}$ were 3 for gerbera, and 2 for sunflower.

Effect of storage temperature on vase life and flower quality. For both gerberas and sunflowers, storage at $0{ }^{\circ} \mathrm{C}$ resulted in a poststorage vase life at $20^{\circ} \mathrm{C}$ that was indistinguishable from that of the initial controls (Figs. $1 b$ and $2 b$ ). The vase life of the nonstored flowers was $15.0 \mathrm{~d}$ for gerberas and $6.3 \mathrm{~d}$ for sunflowers. As the storage temperature increased, the vase life of the flowers fell, so that flowers stored dry at $10{ }^{\circ} \mathrm{C}$ had only half the vase life of those stored at $0{ }^{\circ} \mathrm{C}$.

After removal from dry storage, the scapes of all the gerberas stored at temperatures above $0{ }^{\circ} \mathrm{C}$ were bent as a result of negatively gravitropic growth (Figs. 3 and 6). With time in the vase, the flowers held at 2.5 and $5{ }^{\circ} \mathrm{C}$ recovered, but flowers stored at higher temperatures remained bent (Fig. 3). For the massive scapes of sunflowers, bending after $2 \mathrm{~d}$ was highly correlated with storage temperature (Fig. 4). In both flowers, the bending was 

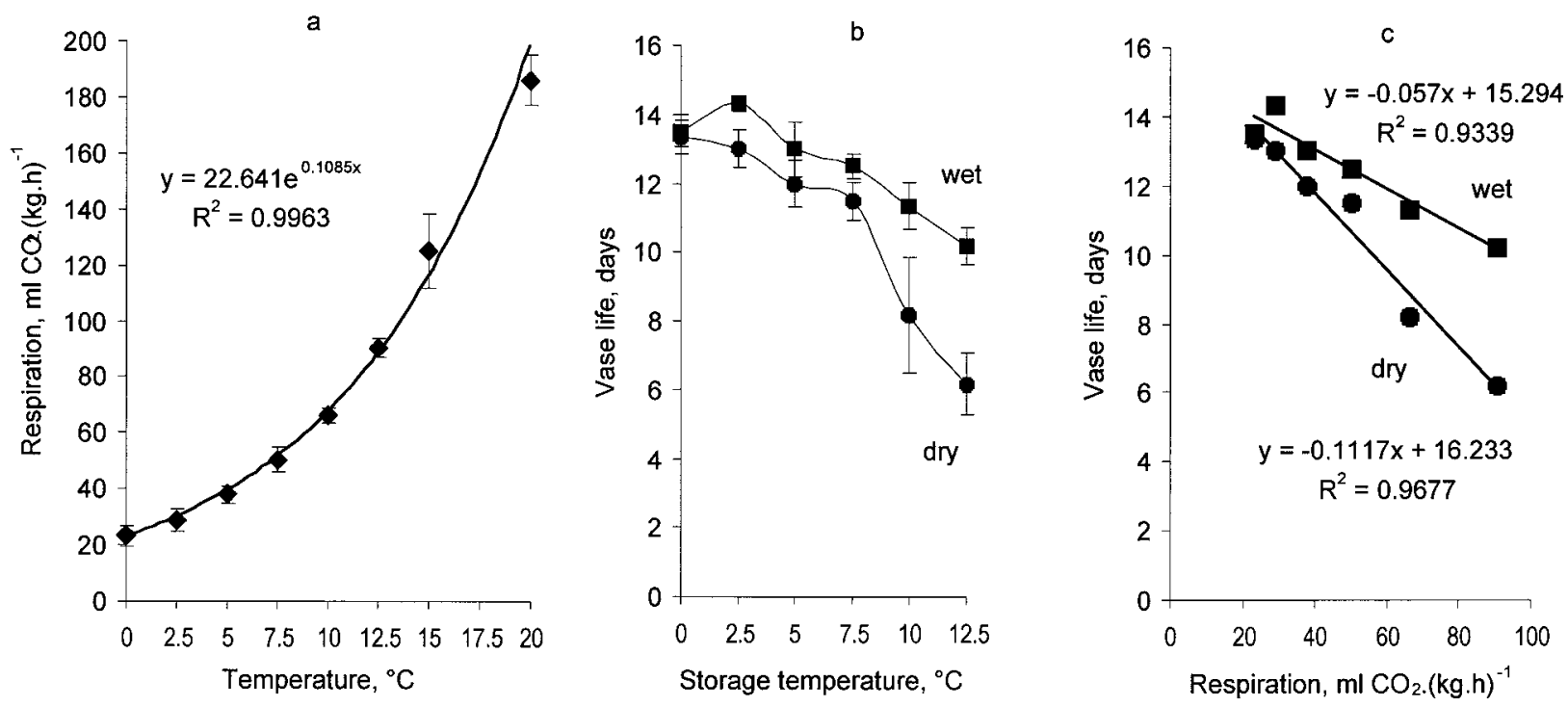

Fig. 1. (a) Respiration rates at different temperatures; (b) vase life at $20^{\circ} \mathrm{C}$ after $5 \mathrm{~d}$ of dry or wet storage at different temperatures; and (c) relationship between vase life and respiration of dry- and wet-stored gerbera flowers. Vertical bars in Fig. 1 a and b show standard errors of three and six replicate flowers, respectively, for each temperature. The vase life of the nonstored flowers was $15 \pm 0.4 \mathrm{~d}$ (mean $\pm \mathrm{SD}$ ).
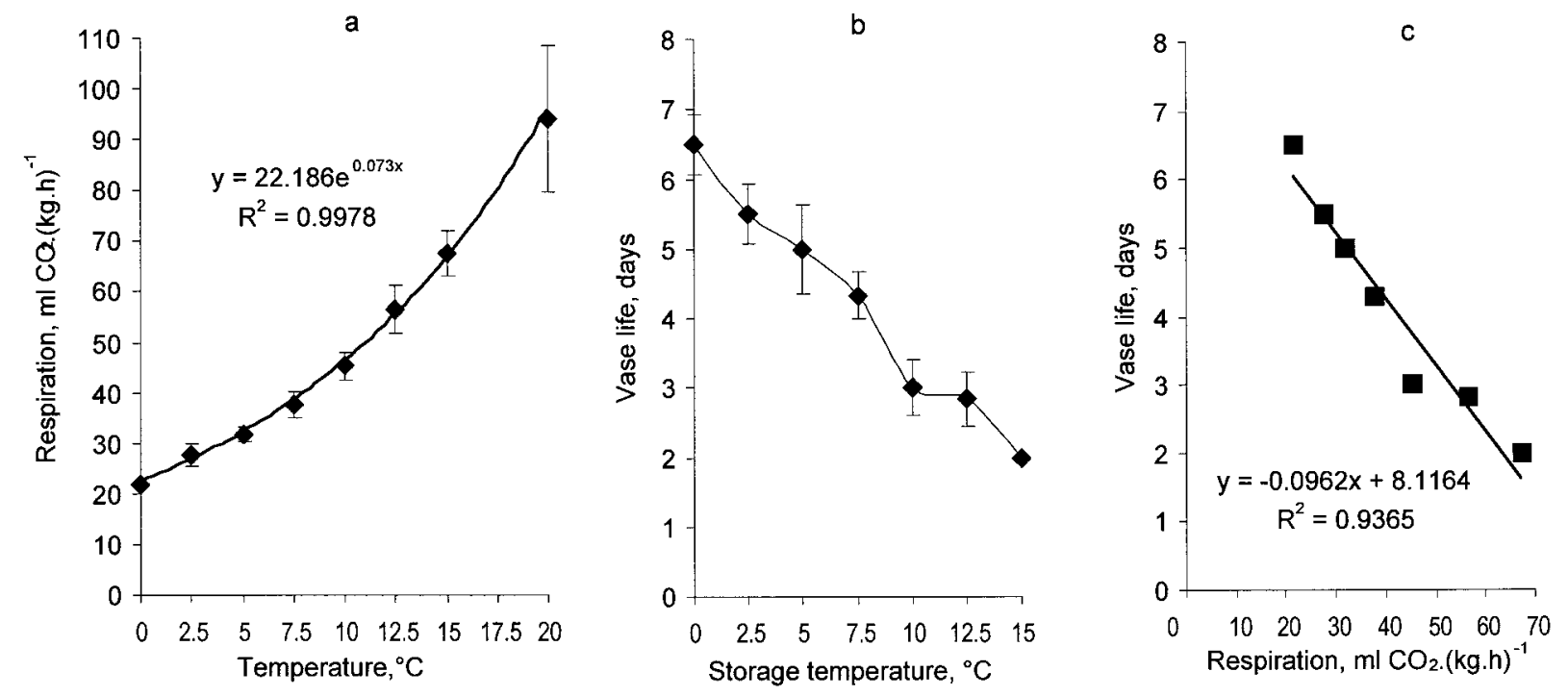

Fig. 2. (a) Respiration rates at different temperatures; (b) vase life at $20^{\circ} \mathrm{C}$ after $5 \mathrm{~d}$ of dry storage at different temperatures; and (c) relationship between vase life and respiration of sunflower. Vertical bars in Fig. $2 \mathrm{a}$ and $\mathrm{b}$ show standard errors of three and six replicate flowers, respectively, for each temperature. The vase life of the nonstored flowers was $6.3 \pm 1.4 \mathrm{~d}$ (mean $\pm \mathrm{sD}$ ).

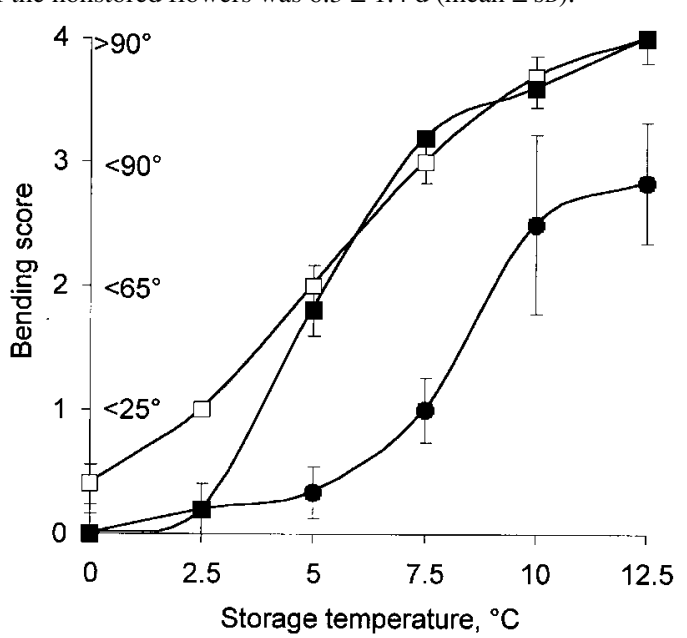

Fig. 3. Scape bending of gerbera flowers stored horizontally in dry storage for 5 $\mathrm{d}$ at various temperatures and then held in the vase at $20^{\circ} \mathrm{C}$ for $0(\square-\square), 1(\square-$ $\mathbf{\square})$, and $3(-\mathbf{-})$ d. Vertical bars show standard errors of six replicate flowers.

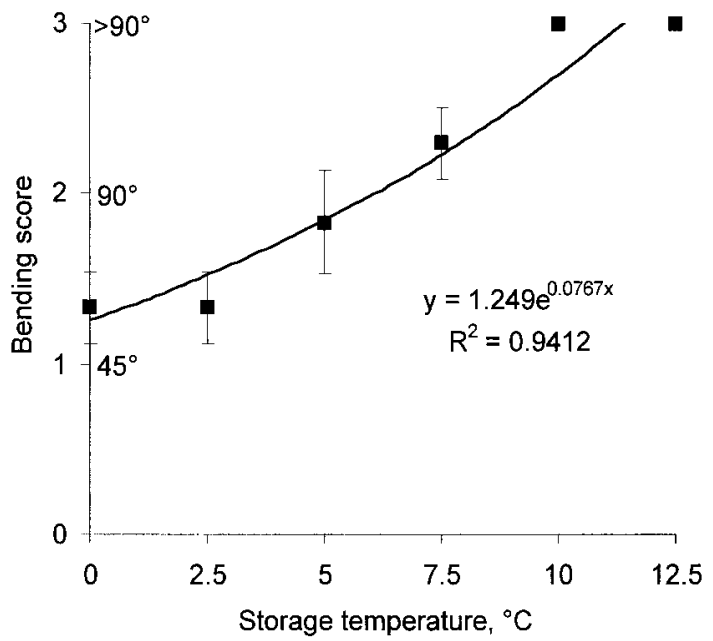

Fig. 4. Relationship between gravitropic bending and $6 \mathrm{~d}$ of dry storage temperatures for sunflower after $2 \mathrm{~d}$ in vase. Vertical bars show standard errors of six replicate flowers. 
a growth effect and did not reflect the loss of turgor in the scapes.

Storage at warm temperatures also affected the opening of sunflowers. After $2 \mathrm{~d}$ in the vase, the ligules on the inflorescences of flowers stored at 0 and $2.5{ }^{\circ} \mathrm{C}$ were displayed horizontally, giving the flowers much larger diameters than those stored at higher temperatures (Fig. 5), which eventually wilted without ever opening properly.

Comparison of wet and dry storage. When gerbera flowers were stored with their bases in water, the effects of temperature on vase life were quite similar to those stored dry in the low part of the temperature range (Fig. 1b). The vase life of flowers stored wet at 10 and $12.5^{\circ} \mathrm{C}$ was significantly better than that of the dry-stored comparison flowers, but was nevertheless significantly less than that of flowers held (wet or dry) at $0^{\circ} \mathrm{C}$.

Relationship between vase life and respiration at different storage temperatures. The vase life of gerberas and sunflowers after storage at different temperatures was highly linearly (and negatively) correlated with the respiration of the flowers at those different temperatures (Figs. 1c and 2c). The slope of the regression was less in wet-stored flowers than in dry-stored flowers (Fig. 1c).

\section{Discussion}

Our data indicate the importance of storing and transporting gerberas and sunflowers at low temperature. These quite different members of the Asteraceae behaved in a similar

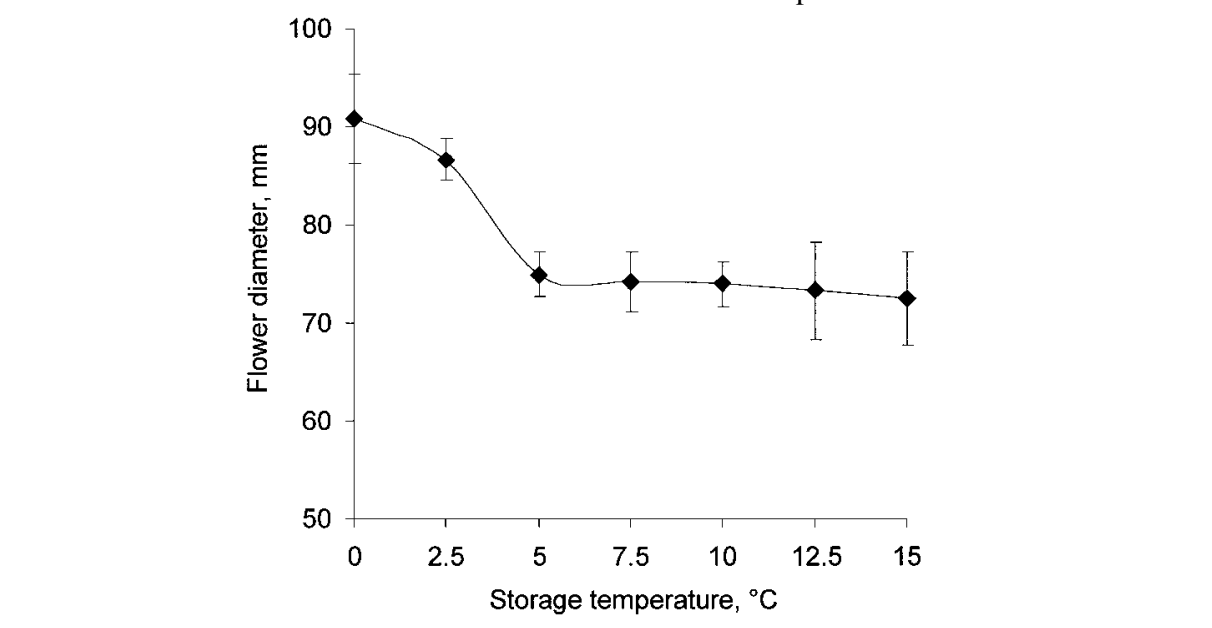

Fig. 5. Flower diameter of sunflower on day 2 in the vase after $6 \mathrm{~d}$ of dry storage at different temperatures. Vertical bars show standard errors of six replicate flowers.

fashion in our experiments. As the simulated transport temperature increased, the posttransport vase life of the flowers fell substantially in gerberas, and dramatically in sunflowers (Figs. $1 \mathrm{~b}$ and $2 \mathrm{~b}$ ). In addition, the display quality of the flowers, both of which are negatively gravitropic, was considerably reduced after storage at the warmer temperatures because of bending of the scape just below the capitulum (Fig. 6). In gerbera, this bending, which was substantial at all temperatures above $0{ }^{\circ} \mathrm{C}$ after $1 \mathrm{~d}$ in the vase, was corrected in flowers that had been stored at the low end of the temperature range (Fig. 3). In sunflower, the much more massive stem remained bent after the storage period. In addition, the "opening" of sunflowers was compromised by storage at warmer temperatures, which reduced the reflexing of the ligules of the ray florets, thus reducing diameter of the flowers (Fig. 5).

The data demonstrate an exponential rise in respiration with increasing temperature for these compound inflorescences. The increase is particularly marked in gerbera, where the average $Q_{10}$ from 0 to $20^{\circ} \mathrm{C}$ was nearly 3 . The strong correlations between poststorage vase life and respiration during storage in these species (Figs. 1c and 2c) are consistent with the findings of Cevallos and Reid (2000), who suggested that temperature-dependent changes in respiration are largely responsible for the effects of temperature on vase life of a range of other cut flowers. While it may be that these changes are simply a correlation, the closeness of fit and the metabolic implications of respiration for the process of flower senescence

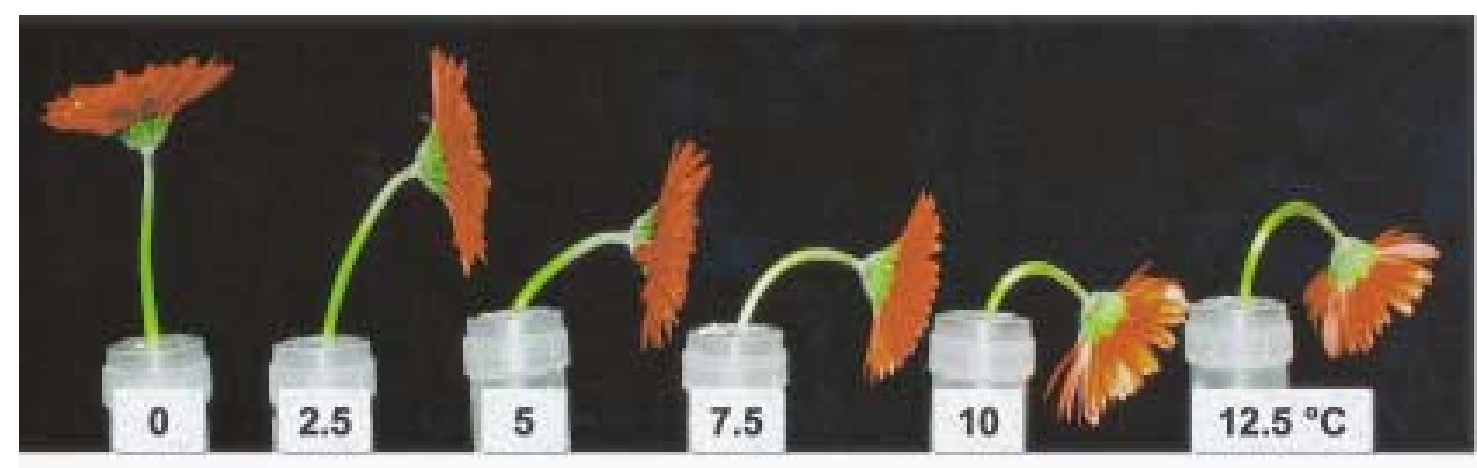

Fig. 6. Effect of $5 \mathrm{~d}$ of dry storage at six different temperatures on scape bending of gerbera flowers immediately after being placed in the vase. 